\title{
Solid Phase Synthesis of Crown Ether's Complexes with Potassium Chlorochromate
}

\author{
Sergei M. Pluzhnik-Gladyr and Sergei A. Kotlyar@ \\ A.V. Bogatsky Physico-Chemical Institute of National Academy of Sciences of Ukraine, Odessa, 65080, Ukraine \\ ${ }^{\circledR}$ Corresponding authorE-mail: kotlyar_sk@mail.ru
}

In the conditions of mechanochemical activation and without the solvent cis-syn-cis-isomer of dicyclohexano-18crown-6, 4I-bromobenzo-18-crown-6, 5,5I-dibromoderivatives of proximal [0.6]biphenyl-20-crown-6 and [1.5]dibenzo18-crown-6 form complexes with potassium chlorochromate $\left(\mathrm{KCrO}_{3} \mathrm{Cl}\right)$ with ratio of 1:1 and 87-99\% yields. At the same time, reactivity of the cis-anti-cis-isomer of dicyclohexano-18-crown-6 is considerably lower: the yield of the (1:1) complex in the similar conditions is only 10\%, and benzo-18-crown-6 and [3.3]dibenzo-18-crown-6 do not take part in the reaction.

Keywords: Dicyclohexano-18-crown-6, benzo- and dibenzocrown ethers, potassium chlorochromate, solid phase synthesis, mechanochemical activation.

\section{Твердофазный синтез комплексов краун-эфиров с хлорохроматом калия}

\author{
С.М. Плужник-Гладырь, С.А. Котляр ${ }^{\circledR}$ \\ Физико-химический институт им. А.В. Богатского Национальной академии наук Украины, \\ Одесса, 65080, Украина \\ ${ }^{@ E-m a i l: k o t l y a r \_s k @ m a i l . r u ~}$
}

\begin{abstract}
В условиях механохимической активации в отсутствие растворителя, ичис-син-иис-изомер дициклогексано18-краун-6, 4I-бромбензо-18-краун-6, 5,5'-дибромпроизводные проксимальных [0.6]бифенил-20-краун-6 и [1.5] дибензо-18-краун-6 образуют комплексы с хлорохроматом калия ( $\mathrm{KCrO}_{3} \mathrm{Cl}$ ) состава 1:1 с выходами 87-99\%. В то же время, реакционная способность ичи-анти-ичис-изомера дициклогексано-18-краун-6 существенно ниже: выход комплекса (1:1) в аналогичных условиях составляет лишь 10\%, а бензо-18-краун-6 и [3.3]дибензо-18краун-6 в обсуждаемую реакцию не вступают.
\end{abstract}

Ключевые слова: Дициклогексано-18-краун-6, бензо- и дибензокраун-эфиры, хлорохромат калия, твердофазный синтез, механохимическая активация.

\section{Введение}

Интенсификация превращения веществ является одной из главных задач современной химии. Механохимия - сложная и бурно развивающаяся область современной химической науки, ее процессы и явления протекают при механической активации твердофазных смесей. Как известно, в результате такой обработки, возрастает реакционная способность твердых веществ, ускоряются химические реакции между твердофазными компонентами, либо сама твердофазная реакция протекает в момент механохимического воздействия. [1-8] Замена жидкостных технологий на «сухие», не требующие использования различного рода растворителей и их последующего удаления и регенерации, актуальна не только в малотоннажном органическом синтезе, но и при получении комплексных соединений.

Осуществляя поиск новых эффективных путей синтеза комплексов краун-эфиров (КЭ) типа «хозяингость» (см., например ${ }^{[9-22]}$, мы использовали метод механохимической активации для изучения комплексообразования этих макроциклов с хлорохроматом калия $\mathrm{KCrO}_{3} \mathrm{Cl}$. Комплексы последнего с различными алифатическими, цикло- и дициклоалифатическими, бензо- и дибензоКЭ ранее получены нами в кислых водных растворах, двухфазных системах либо в среде органических растворителей. Строение и состав многих из них, часто являющихся оригинальными супрамолекулярными объектами, установлены с помощью рентгеноструктурного анализа (РСА). 
В настоящем сообщении изложены первые результаты исследований, проведенных в последнее время.

\section{Экспериментальная часть}

Твердофазный синтез проводили в электромеханической герметичной вибрационной агатовой ступке «КМ-1» (Германия). УФ спектры снимали на приборе VSU 2P, в диапазоне 360-380 нм, кювета толщиной 0,2 см.

Краун-соединения 1-7 и $\mathrm{KCrO}_{3} \mathrm{Cl}$ содержали не менее $98 \%$ основного вещества. Физико-химические характеристики продуктов твердофазного синтеза 8-12 сопоставляли с таковыми для комплексов-свидетелей, полученных в среде этилацетата. ${ }^{[13-16,23]}$ Элементный анализ (определение С и Н) проводили на приборе Perkin-Elmer 2400, серии II, содержание хрома(VI) в комплексах 8-12 определяли прямым титрованием солью Мора либо спектрофотометрически, содержание хлора - титриметрически.

ичис-син-циис-Дициклогексано-18-краун-6· $\mathrm{KCrO}_{3} \mathrm{Cl}(1: 1), \mathbf{8}$ : Смесь иис-изомера 1 (234 мг, 0,63 ммоль) и $\mathrm{KCrO}_{3} \mathrm{Cl}$ (100 мг, 0,57 ммоль) подвергали (2 ч) механохимической обработке в электромеханической вибрационной ступке, амплитуда - 14 . Смесь перемешивали с 5 мл $н$-гексана, фильтровали, твердый остаток промывали 3 мл сухого холодного этилацетата, осадок отфильтровывали, сушили при пониженном давлении до постоянной массы. Выход 310 мг (99\%). т. разл. $149-150{ }^{\circ} \mathrm{C}$ (лит. $148-151{ }^{\circ} \mathrm{C}^{[12]}$ ). Найдено, \%: С 43,99, Н 6,58, Cl 6,57, $\mathrm{Cr} 9,64 . \mathrm{C}_{20} \mathrm{H}_{36} \mathrm{ClCrKO}_{9}$. Вычислено, \%: С 43,91, Н 6,63, Cl 6,48, Cr 9,50.

ичис-анти-ичис-Дициклогексано-18-краун-6· $\mathrm{KCrO}_{3} \mathrm{Cl}$ (1:1), 9: Выход 32 мг (10\%). т. разл. $165-168{ }^{\circ} \mathrm{C}$ (лит. $\left.165-168{ }^{\circ} \mathrm{C}^{[23]}\right)$. Найдено, \%: C 44,02, Н 6,60, Cl 6,53, Cr 9,60. $\mathrm{C}_{20} \mathrm{H}_{36} \mathrm{ClCrKO}_{9}$. Вычислено, \%: С 43,91, Н 6,63, Сl 6,48, Cr 9,50.

4'-Бромбензо-18-краун-6· $\mathrm{KCrO}_{3} \mathrm{Cl}(1: 1), 10:$ Выход 277 мг (99\%). т. разл. $166-167{ }^{\circ} \mathrm{C}$ (лит. $162-165{ }^{\circ} \mathrm{C}^{[14]}$ ). Найдено, \%: С 34,05, Н 4,11, Cr 9,25\%. C ${ }_{16} \mathrm{H}_{23} \mathrm{BrClCrKO}_{9}$. Вычислено, \%: C $33,97, \mathrm{H} \mathrm{4}, 10$, Cr 9,19.

5,5'-Дибром[0.6]бифенил-20-краун-6. $\mathrm{KCrO} \mathrm{Cl}_{3}$ (1:1), $\mathbf{1 1 :}$ Выход 218 мг (87\%). т. разл. $146-147^{\circ} \mathrm{C}$. Найдено, \%: С 36,80, $\mathrm{H} \mathrm{3,77,} \mathrm{Cr} \mathrm{7,10,} \mathrm{Cl} \mathrm{4,88} \mathrm{\% .} \mathrm{C}_{22} \mathrm{H}_{26} \mathrm{Br}_{2} \mathrm{ClO}_{9} \mathrm{CrK}$. Вычислено, \%: C 36,66, H 3,64, Br 22,17, Cr 7,21, Cl 4,92.

5,5'-Дибром[1.5]дибензо-18-краун-6. $\mathrm{KCrO}_{3} \mathrm{Cl}$ (1:1), 12: Выход 312 мг (93\%). т. разл. 192-194 ${ }^{\circ} \mathrm{C}$. Найдено, \%: С 34,57, Н 3,11, Cr 7,38; Cl 5,02. $\mathrm{C}_{20} \mathrm{H}_{22} \mathrm{Br}_{2} \mathrm{ClO}_{9} \mathrm{CrK}$. Вычислено, \%: С 34,68, $\mathrm{H} 3,20, \mathrm{Cr} 7,51 ; \mathrm{Cl} 5,12$.
Синтез комплексов 8-12 в среде этилацетата. При перемешивании, к насыщенному раствору $\mathrm{KCrO}_{3} \mathrm{Cl}$ (2 ммоль) в сухом этилацетате прибавляли раствор краун-соединения 1-5 (2 ммоль) в этилацетате $\left(20^{\circ} \mathrm{C}\right)$. Перемешивали 10 мин; образовавшийся желто-оранжевый кристаллический осадок отделяли фильтрацией, последовательно промывали 2-3 мл холодного этилацетата и 2-3 мл холодного эфира, сушили при пониженном давлении до постоянной массы. Комплексы 8-12 получены с выходами 74-96\%.

\section{Обсуждение результатов}

Авторам не известны примеры использования механохимической обработки (активации) для получения комплексов КЭ с соединениями хрома(VI).

Мы исследовали и сопоставили реакционную способность различных по своей природе кристаллических краун-соединений, а именно, циис-син-ц̧ис- и uзис-анти-ичи-изомеров дициклогексано-18-краун-6 (1, 2 соответственно), бензо-18-краун-6 (6), [3.3]дибензо18-краун-6 (7), 4'-бромбензо-18-краун-6 (3), а также 5,5-дибромпроизводных проксимальных [0.6]бифенил20-краун-6 (4) и [1.5]дибензо-18-краун-6 (5) (Схема 1).

Обнаружено, что твердофазный синтез можно успешно использовать при получении комплексов $\mathrm{KЭ}$ с $\mathrm{KCrO}_{3} \mathrm{Cl}$, а исследованные макроциклы заметно различаются по своей реакционной способности.

Так, в описанных условиях, изис-син-цуис-изомер 1, за 2 ч практически с количественным выходом образует с $\mathrm{KCrO}_{3} \mathrm{Cl}$ комплекс 8 состава 1:1, содержащий более 99\% основного вещества. В то же время, реакционная способность изис-анти-цุис-изомера 2 заметно ниже, что позволяет изолировать соответствующий комплекс 9 (содержит 98,2\% основного вещества) состава 1:1 с выходом, не превышающим 10\%. Напомним, что комплексы 8 и 9 ранее синтезированы нами в среде этилацетата, а их строение и состав установлены PCA. ${ }^{[12,23]}$

Аналогично описанному выше, макроцикл 3 с количественным выходом образует комплекс 10 (состав 1:1), физико-химические характеристики которого идентичны таковым у комплекса, полученного встречным

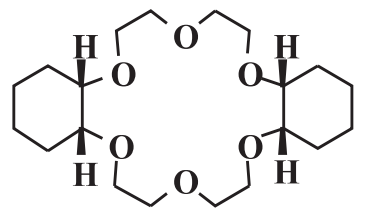

1

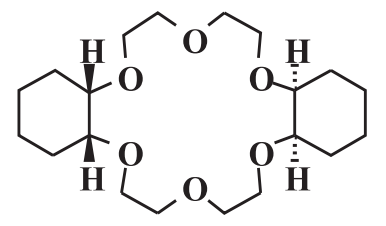

2<smiles>Brc1ccc2c(c1)OCCOCCOCCOCCOCCO2</smiles>

3<smiles>Brc1ccc2c(c1)-c1cc(Br)ccc1OCCOCCOCCOCCOCC2</smiles>

4

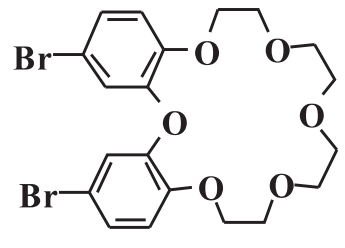

5<smiles>c1ccc2c(c1)OCCOCCOCCOCCOCCO2</smiles>

6<smiles>c1ccc2c(c1)OCCOCCOc1ccccc1OCCOCCO2</smiles>

Схема 1. 
синтезом и идентифицированным РСА.[14] Комплексы 11, 12 состава 1:1 с выходами 97 и 93\%, соответственно, получены впервые из дибромпроизводных 4 и 5.

В то же время, исследованные незамещенные бензо- (6) и дибензоКЭ (7) $\mathrm{c} \mathrm{KCrO}_{3} \mathrm{Cl}$ в реакцию комплексообразования не вступают.

Отметим, что процедура выделения продуктов реакции в чистом виде, проста и эффективна. По окончании процесса формирования комплекса, твердую реакционную смесь при комнатной температуре либо небольшом нагреве обрабатывают $H$-гексаном, при этом полностью удаляется непрореагировавший лиганд. После фильтрации твердый остаток обрабатывают этилацетатом, в котором хорошо растворим не связанный в комплекс хлорохромат. Поскольку целевые комплексы практически не растворимы в указанных растворителях, предложенный способ выделения позволяет получать продукты реактивной чистоты, даже в случае незначительного выхода (комплекс 8).

Состав комплексов 8-12 определяли элементным анализом, температуры разложения комплексов 8-10 хорошо совпадают с литературными данными, а комплексов 11, 12 - с физико-химическими характеристиками соединений, полученных встречным синтезом.

\section{Выводы}

В отличие от твердофазного синтеза, все макроциклы 1-7 легко и с хорошими выходами образуют с $\mathrm{KCrO}_{3} \mathrm{Cl}$ комплексы в среде этилацетата. Предложенный нами ранее способ получения комплексов $\mathrm{K}$ с $\mathrm{KCrO}_{3} \mathrm{Cl}$ в гомогенных условиях смешением этилацетатных растворов лиганда и хлорохромата при комнатной температуре,,$^{[14-16,23]}$ по всей видимости, является достаточно универсальным, поскольку позволяет легко получать и выделять комплексы алифатических, циклоалифатических, незамещенных краун-эфиров, а также бензо- и дибензокраун-эфиров.

После смешения растворов лиганда и «гостя», уже в течение 2-5 минут происходит образование объемного осадка, представляющего собой практически чистый целевой комплекс. Отметим, что выходы комплексов не зависят от природы лиганда и различаются незначительно, изменяясь в интервале 75-90\%.

С учетом вышеизложенного, синтез в твердой фазе может иметь перспективу для изучения реакционной способности КЭ в терминах «структура-свойство».

В то же время, каждый из сложных процессов механохимической активации (или их сочетания) могут инициировать химические превращения, результаты которых также могут быть различными. Известны ${ }^{[3-6]}$ такие макроскопические следствия активации, как смешение компонентов, уменьшение размеров частиц (дробление, диспергирование) и связанное с ним увеличение поверхности твердых фаз, рост числа контактов между частицами.

Кроме того, под действием механохимической активации в кристаллических фазах могут происходить фазовые переходы и накопление различного рода дефектов структур. По современным представлениям, ${ }^{[3-6,8]}$ именно образование дефектов является главным фактором, вызывающим изменение реакционной способности твердого вещества и самопротекание механохимических реакций.

Очевидно, что для выявления особенностей обсуждаемой реакции, следует не только расширить круг исследуемых в твердофазных превращениях краунсоединений, но и вовлечь в процесс другие соединения шестивалентного хрома (бромохроматы, ди-, три- и тетрахроматы).

\section{Список литературы}

\section{References}

1. Simonesku K., Oprel K. Mekhanokhimia Vysokomolekuljarnykh Soedinenii [Mechanochemistry of High Weight Molecular Compounds]. Moskva, Mir, 1970, 614 p. (in Russ.).

2. Hinix H. Tribochimia [Tribochemistry]. Moskva, Mir, 1987, 582 p. (in Russ.).

3. Avvakumov Y.G. Mekhanokhimicheskie Metody Aktivatsii Chimicheskih Processov [Mechanical Methods of Activation of Chemical Processes]. Novosibirsk, Nauka, 1986, 305 p. (in Russ.).

4. Boldyrev V.V. Mechanochemistry of Inorganic Solids, in Advances in Solid State Chemistry (Rao C. N. R., Ed.). New Delhi, Indian National Science Academy, 1986, 400-417.

5. Boldyrev V.V.Zh. Vseross. Khim. Obsch. im. D. I. Mendeleeva 1988, 33, 374-383. (in Russ.).

6. Volkov V.V., Myakishev K.G., Sokolov M.N., Fedin V.P., Gushchin L.A., Ilyinchik Y.A. Khimia $v$ Interesakh Ustoichivogo Razvitia 2005, 13, 155-164. (in Russ.).

7. Kalinovskaya I.V., Karasev V.Y. Zh. Neorg. Khim. 2000, 45, 1488-1490. (in Russ.).

8. Petrova L.A., Makhaev V.D. Zh. Neorg. Khim. 2005, 52, $933-$ 938. (in Russ.).

9. Kotlyar S.A., Zubatyuk R.I., Shishkin O.V., Chuprin G.N., Kiriyak A.V., Kamalov G.L. Acta Crystallogr. 2004, E60, m907-m909.

10. Kotlyar S.A., Zubatyuk R.I., Shishkin O.V., Chuprin G.N., Kiriyak A.V., Kamalov G.L. Acta Crystallogr. 2004, E60, m1015-m1016.

11. Kotlyar S.A., Zubatyuk R.I., Shishkin O.V., Chuprin G.N., Kiriyak A.V., Kamalov G.L. Acta Crystallogr. 2005, E61, m293-m295.

12. Kotlyar S.A., Zubatyuk R.I., Zhigalko M.V., Shishkin O.V., Chuprin G.N., Kiriyak A.V., Kamalov G.L. Acta Crystallogr. 2004, E60, m1847-m1848.

13. Kotlyar S.A., Zubatyuk R.I., Shishkin O.V., Chuprin G.N., Kiriyak A.V., Kamalov G.L. Acta Crystallogr. 2005, E61, $\mathrm{m} 2163-\mathrm{m} 2165$.

14. Kotlyar S.A., Shishkina S.V., Shishkin O.V., PluzhnikGladyr S.M., Kiriyak A.V., Chuprin G.N., Kamalov G.L. Acta Crystallogr. 2006, E62, m120-m122.

15. Kotlyar S.A., Zubatyuk R.I., Shishkin O.V., Kiriyak A.V., Pluzhnik-Gladyr S.M., Kamalov G.L. Acta Crystallogr. 2006, E62, m1790-m1792.

16. Kotlyar S.A., Shishkina S.V., Shishkin O.V., PluzhnikGladyr S.M., Kiriyak A.V., Chuprin G.N., Kamalov G.L. Acta Crystallogr. 2006, E62, m1988-m1989.

17. Kotlyar S.A., Shishkina S.V., Shishkin O.V., Grygorash R. Ya., Pluzhnik-Gladyr S.M., Kamalov G.L. Acta Crystallogr. 2007, E63, o2904.

18. Kotlyar S.A., Fonari M., Simonov Yu.A., Bocelli G., Shishkin O.V., Shishkina S.V., Tkachuk V.V., Grygorash R. Ya., Kamalov G.L. J. Inclusion Phenom. 2005, 52, 75-84. 
19. Yakshin V.V., Vilkova O.M., Kotlyar S.A. Dokl. Ross. Akad. Nauk 2000, 374, 214-217. (in Russ.).

20. Yakshin V.V., Vilkova O.M., Kotlyar S.A., Grigorash R.Ya. Dokl. Ross. Akad. Nauk 2001, 379, 80-82. (in Russ.).

21. Kamalov G.L., Kotlyar S.A., Grygorash R.Ya., Tkachuk V.V., Chuprin G.N., Shishkin O.V., Konup I.P., Konup L.A. In
Oxygen and Sulfur Containing Heterocycles (Kartsev V. G., Ed.) Moscow, IBS PRESS, 2003, 238-244.

22. Kotlyar S.A., Pluzhnik-Gladyr S.M. Macroheterocycles 2008, 1, 85-89.

23. Chuprin G.N. Avtorefer. Diss. Kand. Khim. Nauk. A.V. Bogatsky Physico-Chemical Institute of National Academy of Sciences of Ukraine, 2007, Odessa, 24 p.

Received 18.11.2008

Accepted 05.12.2008

First published on the web 04.02.2009 